"An involution of rays contains one, but only one, rectangular pair." On the next page, likewise in italics, is a second theorem: "An involution having more than one rectangular pair has all its pairs rectangular." These two theorems are, on their face, somewhat contradictory. Of course there is no difficulty in understanding their relation to each other, and there might be little cause for comment were it not for the fact that too many instances of this sort of infelicity in style are present. On page 68 the author states: "A plane figure may therefore be considered either as a configuration of points or as a configuration of straight lines. This is the principle of duality." Such a statement seems hardly definite enough to cover the case. The matter of dividing by factors which may be zero, the various special cases which may arise, in fact the whole modern demand for a greater accuracy in geometric work is not sufficiently regarded.* Apart from this the work has much to commend it. And those for whom the book was especially written will probably not think the defect very serious. To the reader, whoever he be, the uncommonly good index will be of great service.

E. B. WiLson.

Differential- und Integralrechnung; Zweiter Band: Integralrechnung. Von W. Franz Meyer. Mit 36 Figuren. Leipzig, C. J. Göschensche Verlagshandlung (Sammlung Schubert, number XI), $1905 . \quad 16+443 \mathrm{pp}$.

THE present volume is a direct continuation of the preceding one on differential calculus, to which constant references are made. Integration is first defined as the inverse of differentiation. It is treated analytically and applied to elementary algebraic, logarithmic, and trigonometric functions. The idea of summation is introduced by a very detailed discussion of successive approximations to the area of the parabola, then extended to any plane curve, first with equal intervals, then for any law of division. The oscillation of a function, and superior and inferior integrals are repeatedly mentioned and strongly emphasized.

The first theorem of mean value is introduced by the aid of a figure, then made precise and applied to several problems.

\footnotetext{
* See for example M. Bôcher on "A problem in analytic geometry with a moral," Annals of Math., vol. 7, p. 44 (October, 1905).
} 
Areas defined by polar coördinates are first treated by means of transformation of the variables after the rectangular coördinates have been discussed; but a good geometric discussion is added. Maclaurin's series and allied formulas are treated at some length, the forms of the remainder being minutely compared with the forms derived in differential calculus, but the difficulties of a double or multiple limit receive but little attention.

Chapter 2 is concerned with quadrature, complanation, and rectification. The idea of length is carefully defined and a very large number of illustrations are brought in, but all are worked out in full, leaving no problems for the student. The two following chapters are devoted to tangents and normals, contact and curvature, and inflexions, treated by the usual methods of the differential calculus. The author explains in the preface that these subjects were excluded from the preceding volume on account of its size.

It seems remarkable that when nearly three hundred pages have been covered, over half of them dealing with applications, only a very limited number of forms of integrals have been derived. Much space could have been spared by a different arrangement. In the latter part of the book (pages 281-370) a long chapter is devoted to systematic integration, very similar to the plan followed by the better American text-books, though many more details are given, leaving fewer steps for the student to supply. As a natural extension of this chapter another follows on elliptic integrals, the addition theorems of elliptic, hyperbolic, and circular functions, and integration in series. The last topic, double integration, occupies about twenty pages. These include the fundamental definitions, discussion of limits, change of sequence, transformations of the variables, and a few applications to cubature and complanation.

The book contains a number of instructive features, many problems are treated by new methods, but the arrangement of topics seems unfortunate for a student. The book is full of helpful cross references, but is not provided with an index.

VIRGIL SNYDER.

\section{Le Calcul des Résidus et ses Applications à la Théorie des Fonc-} tions. By ERnst LindelöF. Paris, Gauthier-Villars, 1905. $141 \mathrm{pp}$.

WE here have a small volume devoted to a relatively narrow though important field of mathematics. The calculus of resi- 